\title{
Fundamentals of Mercury Oxidation in Flue Gas
}

\author{
Technical Annual Report
}

Reporting Period:

August 1, 2004 - July 31, 2005

\author{
JoAnn S. Lighty, PI \\ Geoffrey Silcox, co-PI \\ Andrew Fry, Graduate Student \\ Department of Chemical Engineering \\ University of Utah \\ Constance Senior, co-PI \\ Reaction Engineering International \\ Joseph Helble, co-PI \\ Balaji Krishnakumar, Graduate Student \\ Department of Chemical Engineering \\ University of Connecticut \\ Submitted: \\ August 2005 \\ Department of Chemical Engineering \\ 50 South Central Campus Drive \\ Room 3290 MEB \\ University of Utah \\ Salt Lake City, UT 84112
}

DOE Grant Number DE-FG26-03NT41797 


\section{DISCLAIMER}

This report was prepared as an account of work sponsored by an agency of the United States Government. Neither the United States Government nor any agency thereof, nor any of their employees, makes any warranty, express or implied, or assumes any legal liability or responsibility for the accuracy, completeness, or usefulness of any information, apparatus, product, or process disclosed, or represents that its use would not infringe privately owned rights. Reference herein to any specific commercial product, process, or service by trade name, trademark, manufacturer, or otherwise does not necessarily constitute or imply its endorsement, recommendation, or favoring by the United States Government or any agency thereof. The views and opinions of authors expressed herein do not necessarily state or reflect those of the United States Government or any agency thereof. 


\begin{abstract}
The objective of this project is to understand the importance of and the contribution of gas-phase and solid-phase coal constituents in the mercury oxidation reactions. The project involves both experimental and modeling efforts. The team is comprised of the University of Utah, Reaction Engineering International, and the University of Connecticut. The objective is to determine the experimental parameters of importance in the homogeneous and heterogeneous oxidation reactions; validate models; and, improve existing models. Parameters to be studied include $\mathrm{HCl}$, $\mathrm{NOx}$, and $\mathrm{SO}_{2}$ concentrations, ash constituents, and temperature.

This report summarizes Year 2 results for the experimental and modeling tasks. Experiments in the mercury reactor are underway and interesting results suggested that a more comprehensive look at catalyzed surface reactions was needed. Therefore, much of the work has focused on the heterogeneous reactions. In addition, various chemical kinetic models have been explored in an attempt to explain some discrepancies between this modeling effort and others.
\end{abstract}




\section{TABLE OF CONTENTS}

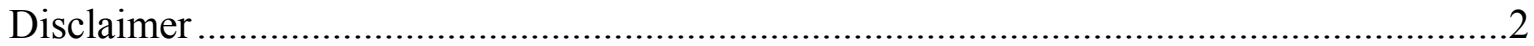

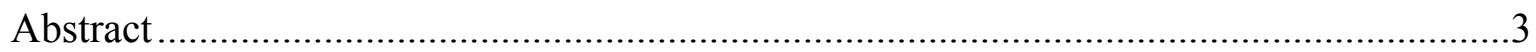

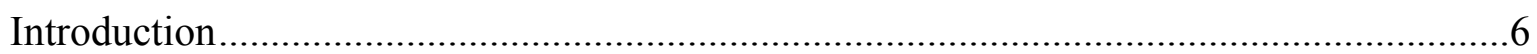

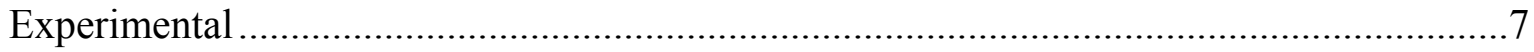

Mercury Reactor Furnace and Mercury Analyzer .....................................................

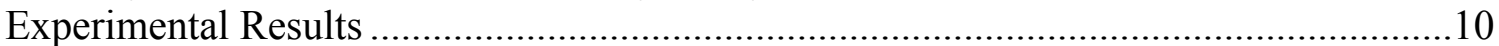

Modeling Chemistry in Mercury Flue Gas ...................................................................15

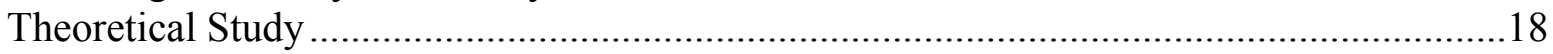

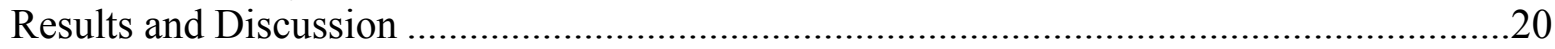

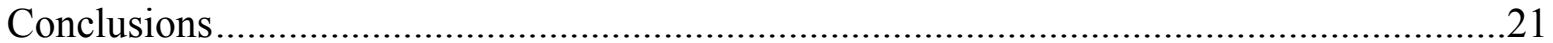

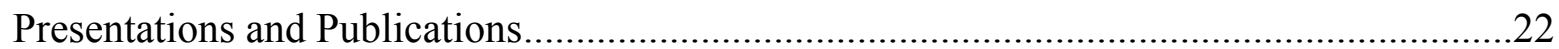

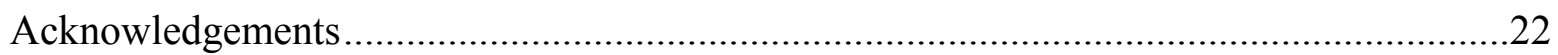

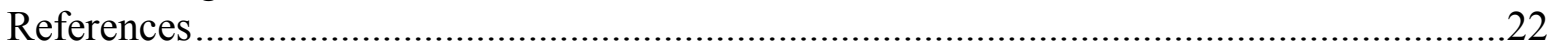




\section{LIST of TABLES and FIGURES}

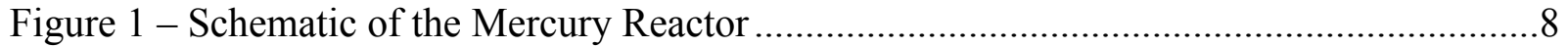

Figure 2 - Mercury Analysis System............................................................................ 9

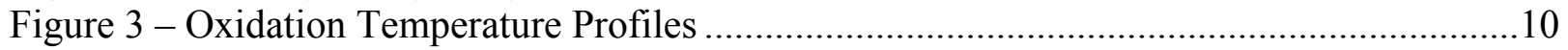

Figure 4 - Oxidation Dependence on Temperature Profile ..................................................11

Figure 5 - UofU High and Low Quench Oxidation Data Compared with Oxidation Date of Sliger (2000) and Mamani-Paco (2000) .................................................................... 12

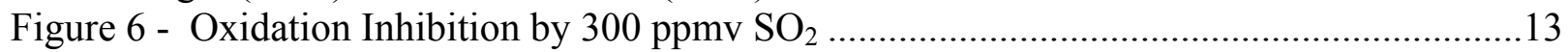

Figure 7 - Mercury Speciation Data Showing Adsorption and Desorption of Mercury .............14

Figure 8 - Mercury Adsorption Dependence on Chlorine Concentration................................15

Figure 9. - UConn $\mathrm{Hg}$ reactions analyzed using three chlorine recombination reactions ...........17

Figure 10 - Wilcox Hg reactions analyzed using three chlorine recombination reactions .........17

Figure 11 - Comparison of Model Prediction and Experiment, High Quench Temperature

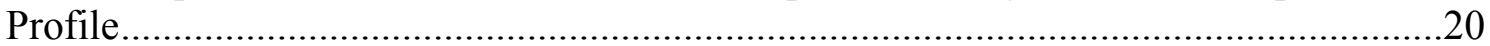

Figure 12 - Comparison of Model Prediction and Experiment, Low Quench Temperature Profile.....

Table 1 - Reaction Rate Parameters for Reaction 9 .16

Table 2 - Mercury Oxidation under Different Chlorine and Mercury Reaction Mechanisms ....18

Table 3 - Comparison of Experimental and Calculated Parameters for $\mathrm{HgCl}$ .19 


\section{INTRODUCTION}

The objective of this project is to understand the importance and contribution of gas-phase and solid-phase constituents in the reactions of mercury oxidation. Included in the investigation are the effects of chlorine concentrations, NOx concentration, $\mathrm{SO}_{2}$ concentration, and reactions with ash constituents. A wet flue gas desulfurization system can remove most of the oxidized gaseous mercury in a coal-fired power plant. In addition, oxidized mercury is more likely to adsorb on fly ash, and, hence, be removed by the particulate control device, or be adsorbed by activated carbon. This removal uses existing equipment and requires no additives, making it a low-cost option. However, elemental mercury cannot be removed effectively using these methods. By understanding the important mechanisms in mercury oxidation, a greater fraction of the $\mathrm{Hg}$ could be captured using "back end" technology.

The project team includes the University of Utah, Reaction Engineering International, and the University of Connecticut. The team will collaborate on an experimental and modeling effort that will involve determination of experimental parameters, validation of the model, and improvement of existing models. Two stages of experiments were proposed; at this point, some realignment of the experimental matrix will take place. Gas- and particle-phase constituents will be doped to determine the importance of specific parameters, such as $\mathrm{HCl}, \mathrm{NOx}, \mathrm{SO}_{2}$, and ash constituents.

Three tasks were envisioned:

\section{Task 1.0 - Experimental Investigation of Mercury Chemistry}

The University of Utah will perform natural gas and coal combustion experiments in both a mercury reactor (Phase 1) and a facility with realistic time/temperature histories (Phase 2). The experiments will utilize "doped" constituents to investigate the importance of these constituents in the mercury oxidation mechanism. Both gas $(\mathrm{HCl}, \mathrm{NOx}$, and $\mathrm{SO} 2)$ and solid (e.g. iron, calcium) constituents will be investigated.

\section{Task 2.0 - Model Validation}

REI and UConn will use existing versions of mercury oxidation models in the flue gas to guide the experimental design, predicting ranges of process parameters, e.g. temperature, chlorine concentration, and nitrogen oxide concentration, which would produce measurable changes in mercury speciation. UConn will focus on mechanism development; REI will focus on modeling and interpretation of experiments. The experimental data will be used to validate the gas-phase oxidation model (and improve it, if needed). The data will also clearly identify the effects of heterogeneous oxidation, as distinct from homogeneous oxidation. This information will be used to validate and improve heterogeneous models for mercury oxidation on fly ash.

\section{Task 3.0 - Evaluation of Control Strategies}

The effectiveness of mercury control strategies varies depending on the speciation of mercury in the flue gas. As a result of the experimental and model validation activities, we will be better able to predict the speciation of mercury in flue gas for a wide range of 
coal types and conditions. We will use this information to recommend modifications to existing control strategies or to suggest new control strategies, if they arise.

The results to date have suggested that some heterogeneous mercury oxidation might be occurring on the walls of the quartz reactor. The experiments have focused on trying to identify this complexity and the extent to which it is important. Given this focus on gas-phase chemistry, it is unlikely that tests will be performed with coal. However, packed-bed and dispersed-phase experiments will be run on coal constituents, including iron and calcium. Unburned carbon may also be a candidate once other major constituent heterogeneous interactions are understood. The validation of modeling with experimental results has also been accomplished. Using the temperature distribution of the mercury reactor, predictions of gas-phase conversion have been completed. Some of these results have been different from other investigators and this has been further studied.

\section{EXPERIMENTAL}

\section{Mercury Reactor Furnace and Mercury Analyzer}

The mercury reactor used in this study at the University of Utah is shown in Figure 1. A $50 \mathrm{~mm}$ OD $\times 47 \mathrm{~mm}$ ID quartz reaction tube $(127 \mathrm{~cm}$ in length) runs through the center of a hightemperature Thermcraft heater. The section of quartz tube protruding below the heater is temperature-controlled using heat tape and insulation. This allows the temperature profile to be configured for different quench rates. The temperature profile should result in a timetemperature history that is representative of real combustion systems.

To oxidize mercury in a matrix of combustion products and to provide initial conditions for modeling, the mercury reactor has been fitted with a natural gas, premixed burner. In these experiments all reactants are introduced through the burner and pass through the flame. To avoid adsorption of mercury and interference with mercury speciation, the burner is constructed of quartz glass, which has no affinity for elemental mercury. The burner was designed to operate at a rate of approximately 1,000 BTU/hr, producing 6 SLPM of combustion gas.

Integrated into the burner design is a connecting system that allows emergency blow-off without causing contact between mercury-containing gases and surfaces that might react with mercury. A $6.35 \mathrm{~cm}$ diameter stainless steel tee is mounted to the top of the mercury reactor. The $2.54 \mathrm{~cm}$ OD quartz burner is sealed to the top of the tee with graphite packing and extends all the way through into the quartz reaction tube. A quartz washer with a $50 \mathrm{~mm}$ OD and an ID just greater than the burner diameter rests on top of the quartz reaction tube. This washer easily slides up the burner inside the tee. The third nozzle on the tee is blocked with a blow-off diaphragm and the tee is purged with a small fraction of the burner combustion air. Use of flame in the mercury reactor required significant modifications to the reactor control system. A flame detection system was installed. This system uses a UV detector to monitor the status of the flame in the burner. If the flame is extinguished, the control system closes a solenoid valve on the natural gas supply to eliminate the possibility of uncontrolled ignition. 


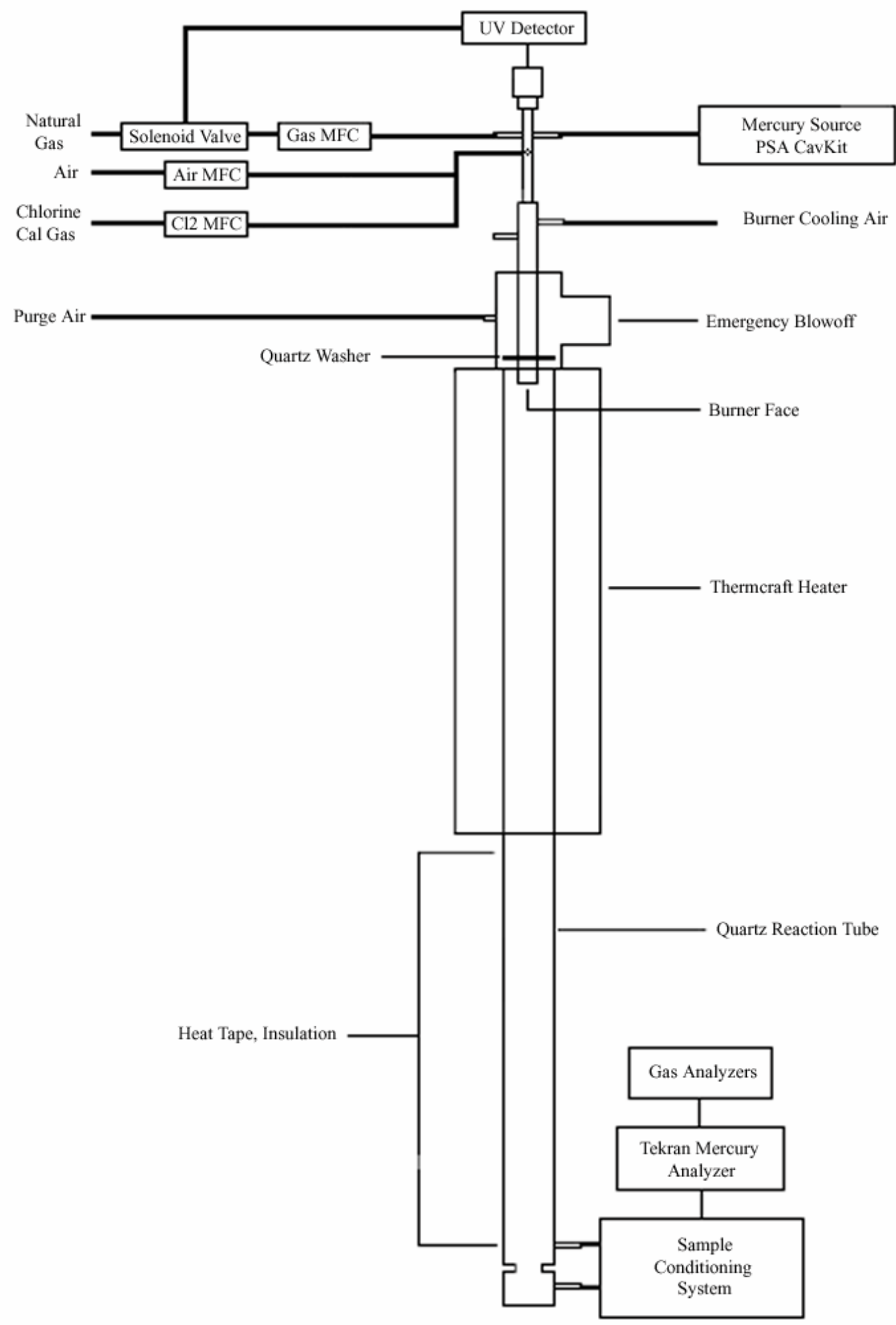

Figure 1. Schematic of the Mercury Reactor 
A sample of flue gas is withdrawn from the bottom of the reactor and enters the sampleconditioning system, designed by Southern Research Institute (SRI). In this system the sample gas is pulled in two streams directly from the last section of the quartz reaction tube into a set of conditioning impingers. One stream is bubbled through a solution of stannous chloride to reduce oxidized mercury species to elemental mercury. The stream then contacts a solution of sodium hydroxide to remove acid gases. This stream represents the total mercury concentration in the reactor. The second stream is first treated with a solution of potassium chloride to remove oxidized mercury species and then is also treated in a caustic solution for acid gas removal. This stream is representative of the elemental mercury concentration in the reactor. Oxidized mercury species are represented by the difference between total and elemental mercury concentrations. Water is removed from the sample gas by a chiller and then each stream is intermittently sent to the analyzer by a valve box connected to the analyzer. Analysis is performed using a Tekran 2537A mercury vapor analyzer. The system, previously reported, is shown in Figure 2.

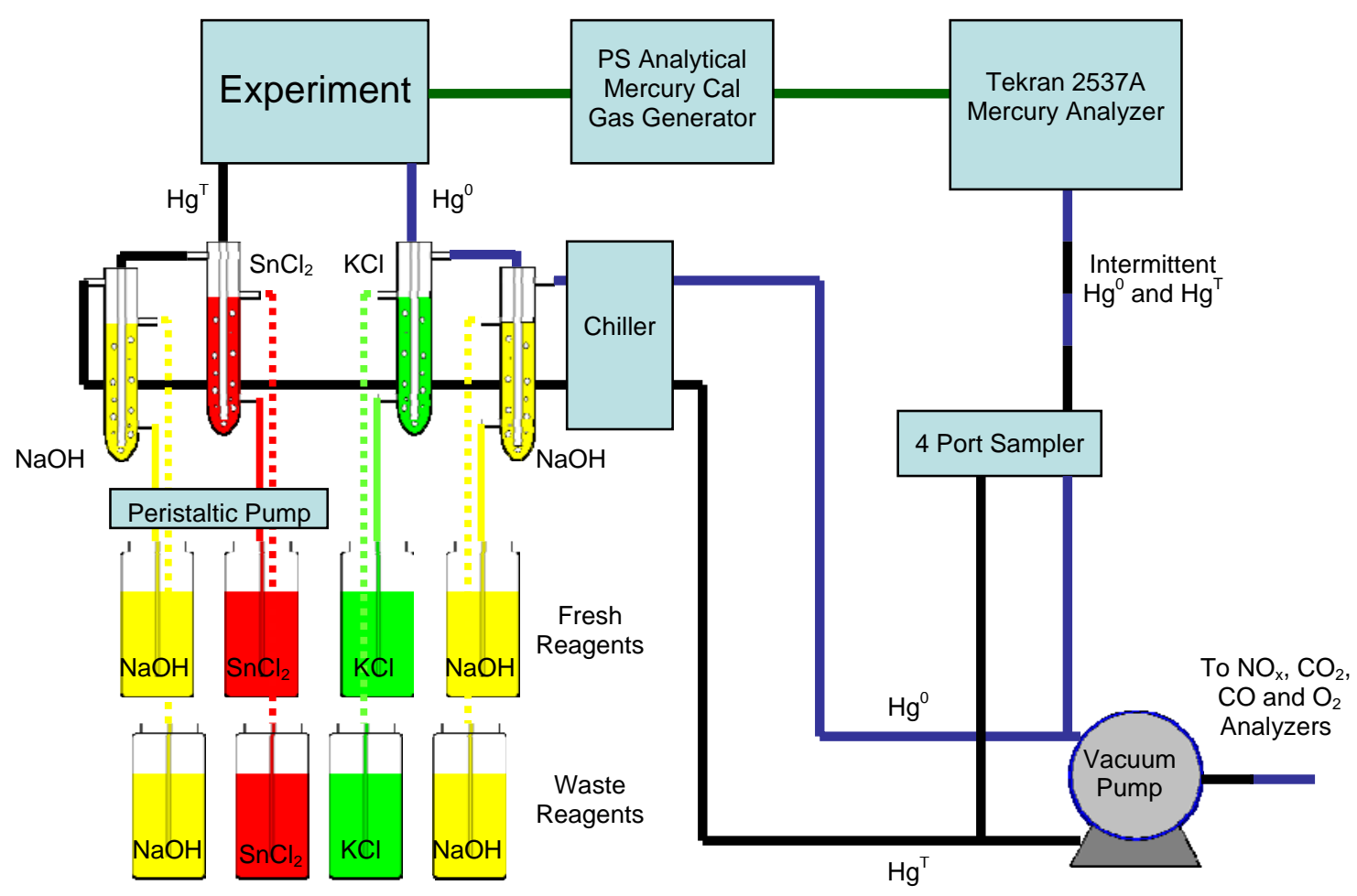

Figure 2. Mercury Analysis System

Variation of reactor configuration resulted in two temperature profiles used for oxidation experimentation. Plots of these temperature profiles are presented in Figure 3. In these profiles a high temperature region is necessary to simulate boiler conditions and to produce the radical pool necessary for mercury oxidation reactions. The quench rates are representative of power 
plant post-combustion conditions. The low temperature region is to represent flue gas temperatures after the air preheaters and through the air pollution control devices. These low temperatures are necessary for oxidation reactions to occur.

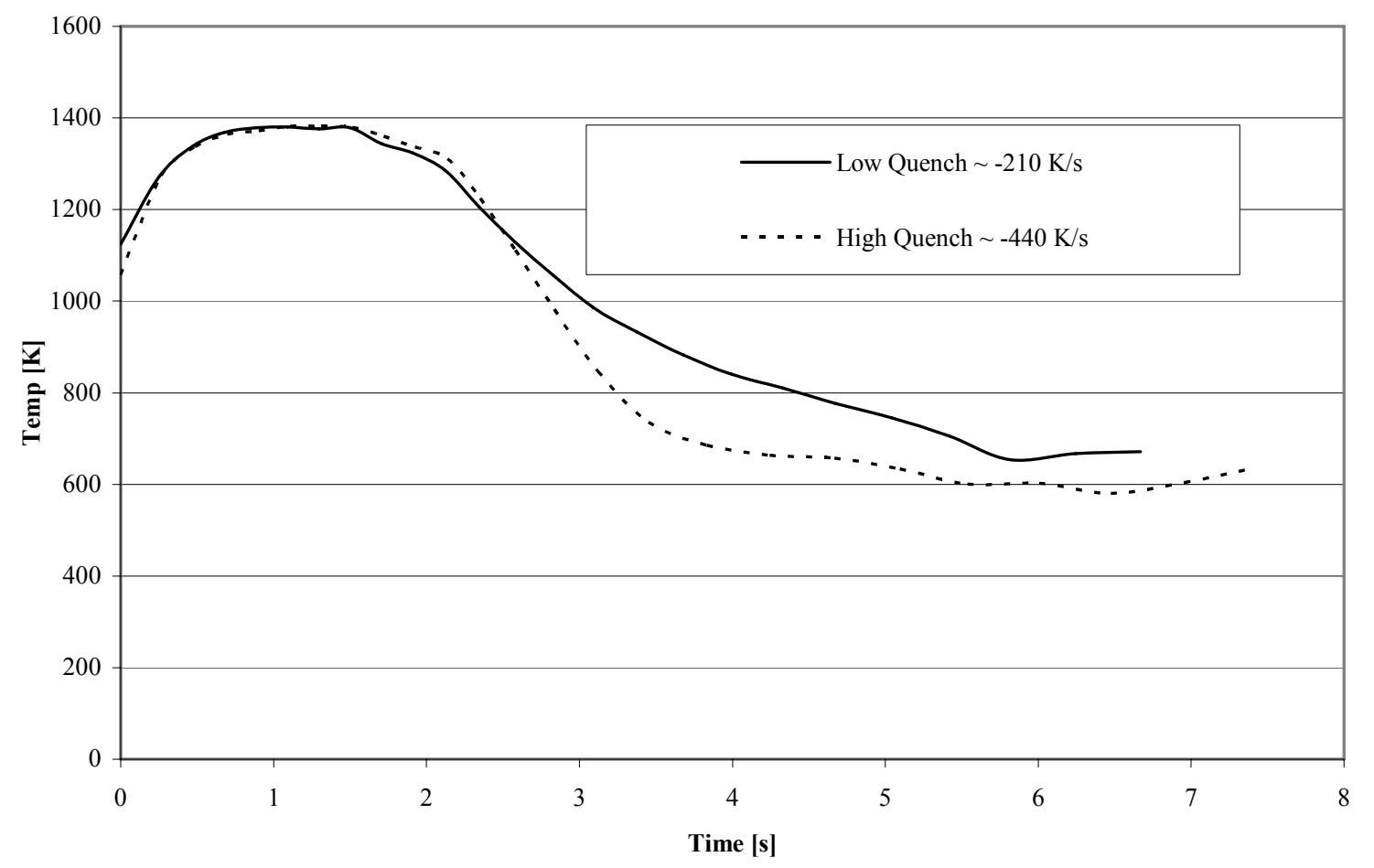

Figure 3. Oxidation Temperature Profiles

\section{Experimental Results}

For each of the temperature profiles detailed in Figure 3, oxidation reactions were performed. Chlorine $\left(\mathrm{as}_{2}\right)$ was introduced into the reactor through the burner using a certified chlorine calibration gas standard in air. The flow of chlorine was controlled using a mass flow controller. It is assumed that as the chlorine molecules pass through the flame they are converted to atomic chlorine and then are converted predominately to $\mathrm{HCl}$. Concentration of chlorine in the reactor was varied from 0 to $600 \mathrm{ppmv}$ and is equivalent to $\mathrm{HCl}$ concentration. Reactor mercury concentration was maintained at $25 \mu \mathrm{g} / \mathrm{m}^{3}$ throughout the experiments. The natural gas burner was fired at its nominal firing rate. The oxidation curves produced from these experiments are detailed in Figure 4, which also gives the composition of the combustion exhaust gas. 


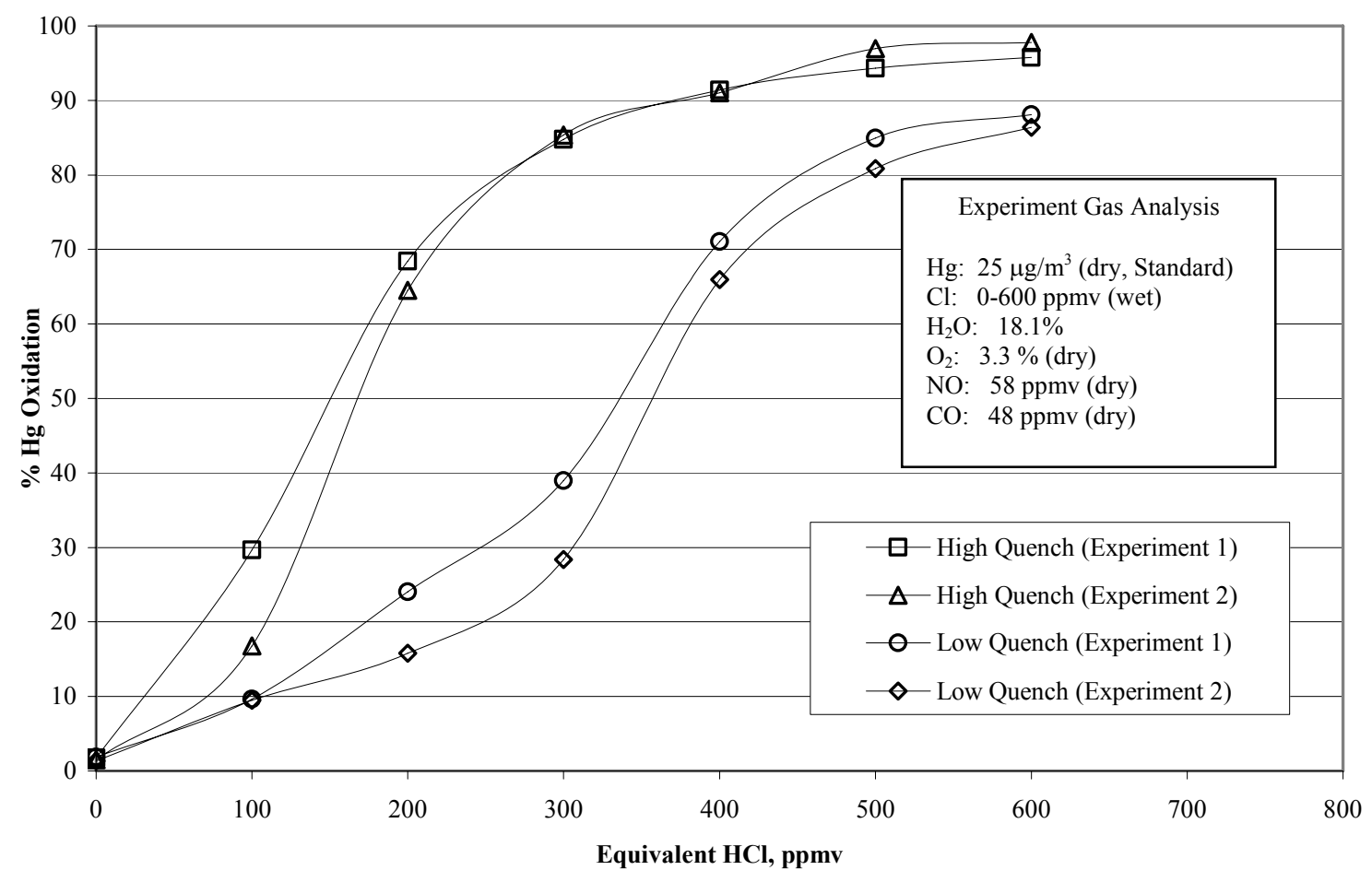

Figure 4

Oxidation Dependence on Temperature Profile

Kinetic control of mercury speciation would suggest that temperature profiles with long residence times at low temperatures should result in significant oxidation. It has also been shown that a high quench rate can result in higher concentrations of chlorine radicals, which can persist at low temperatures (Procaccini, et al. 2000).

Oxidation curves for the high and low quench rates yielded the expected results. In these experiments, the high-quench temperature profile results in significantly higher mercury conversion than the low-quench rate. This can be attributed to longer residence times at low temperatures and possibly higher concentrations of $\mathrm{Cl}$ radicals generated by the higher quench rate. In the high-quench rate experiments, the flue gas was held at less than $650 \mathrm{~K}$ for about 3 seconds, whereas for the low-quench rate experiments, the flue gas was held at less than $650 \mathrm{~K}$ for about 0.8 seconds. Figure 5 is a comparison between these oxidation data and oxidation experiments by Sliger (2000) and Mamani-Paco (2000). Higher oxidation in the current study can be attributed to long residence time at low temperatures and low mercury concentrations.

Error has been evaluated for these data and is presented in the Results and Discussion Section. Error was assigned using the difference between the known elemental mercury concentration at the furnace inlet and the total mercury concentration measured at the furnace outlet at the time each data point was taken. 


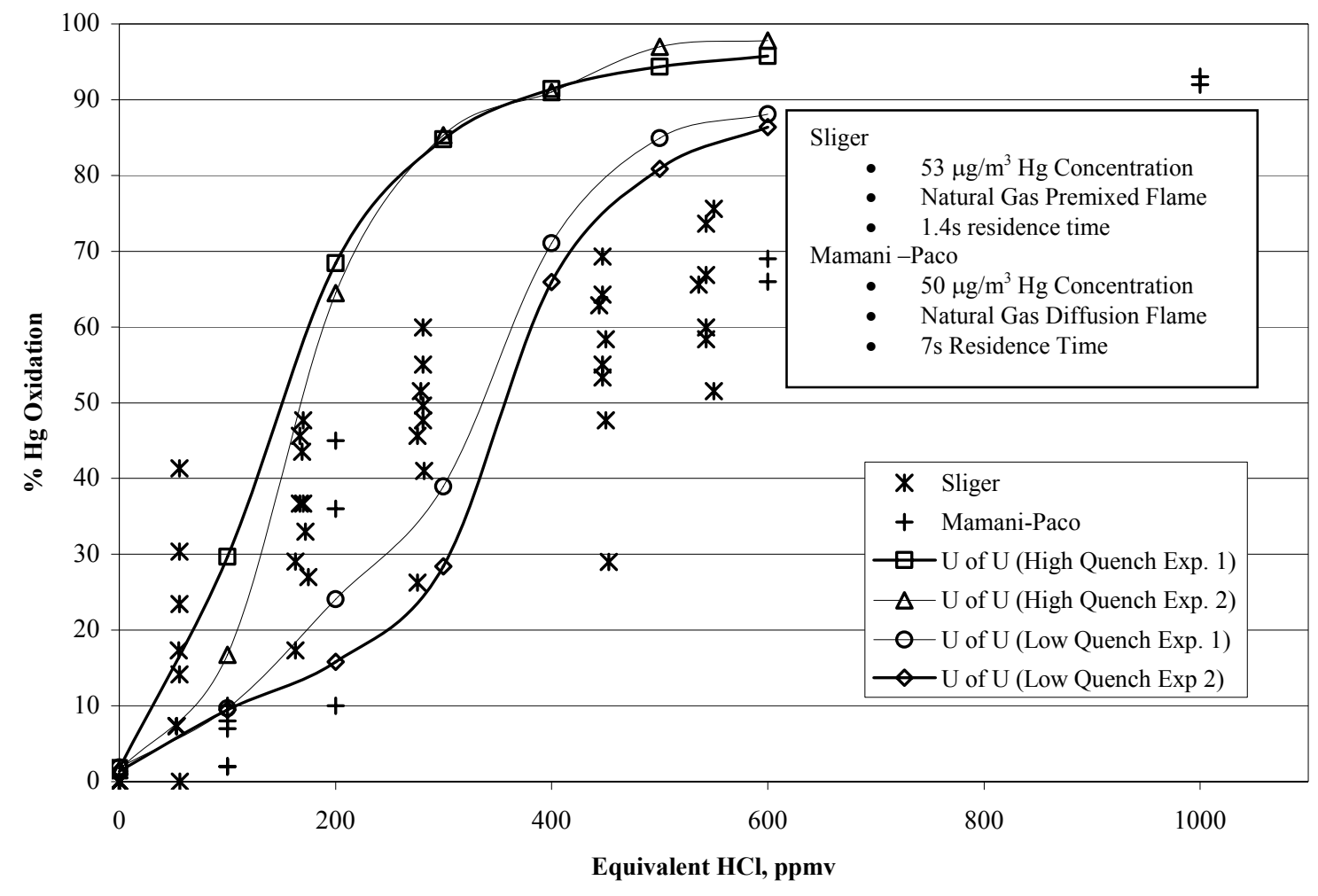

Figure 5

U of U High and Low Quench Oxidation Data Compared with Oxidation Data of Sliger (2000) and Mamani-Paco (2000)

Ghorishi (1998) has shown that $\mathrm{SO}_{2}$ can inhibit mercury oxidation with chlorine. To further investigate these effects, $\mathrm{SO}_{2}$ was injected into the reactor using a certified calibration gas standard. The high quench experiment was repeated while maintaining an $\mathrm{SO}_{2}$ concentration of 300 ppmv in the reactor. The results of this effort are presented in Figure 6.

It has been suggested by Qiu and Helble (2003) that the primary pathway of inhibition is through the removal of $\mathrm{OH}$ and $\mathrm{O}$ radicals by $\mathrm{SO}_{2}$. The removal of these radicals affects the chlorine and subsequently mercury speciation.

Throughout the previously detailed experiments it has become apparent that the quartz walls of the reactor are not completely inert with regard to mercury reactions. Data collected during an oxidation experiment are presented in Figure 7. For this experiment the high quench temperature profile was used. A baseline mercury concentration of $25 \mu \mathrm{g} / \mathrm{m}^{3}$ was achieved. Chlorine was then introduced into the reactor at a concentration of $200 \mathrm{ppmv}$ equivalent $\mathrm{HCl}$. These conditions were maintained for approximately four hours before the chlorine flow to the reactor was eliminated. 


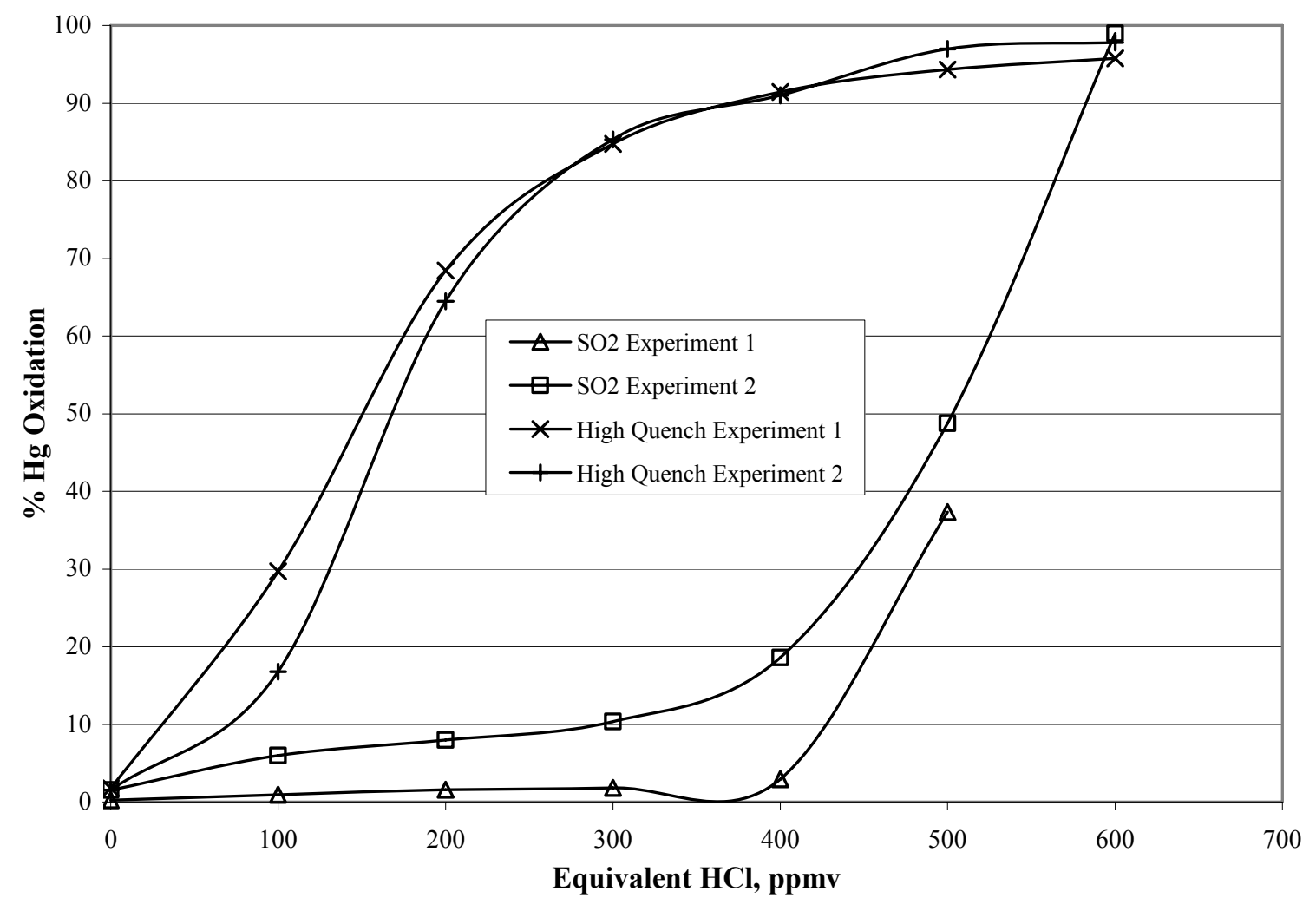

Figure 6

Oxidation Inhibition by 300 ppmv $\mathrm{SO}_{2}$

At the time that the chlorine is introduced into the reactor, the concentration of elemental mercury and total mercury decrease to about $18 \mu \mathrm{g} / \mathrm{m}^{3}$. The reduction in elemental mercury is expected. This would represent conversion to oxidized species when the total mercury concentration is maintained at baseline. The decrease in total mercury concentration suggests that mercury is being adsorbed in the reactor. The first several data points after chlorine addition are approximately the same for both elemental and total mercury. This indicates that oxidation has not yet occurred and all mercury exiting the reactor is elemental. At about 30 minutes from the time of chlorine injection the elemental mercury concentration has stabilized at about 7 $\mu \mathrm{g} / \mathrm{m}^{3}$ and the total mercury has returned to baseline. Data in this region of the plot represent oxidation of just over $70 \%$ as is reported for the high quench temperature profile at $200 \mathrm{ppmv}$ equivalent $\mathrm{HCl}$. At the time that the chlorine is discontinued in the reactor the total mercury increases above the baseline concentration to about $31 \mu \mathrm{g} / \mathrm{m}^{3}$ and then slowly returns to baseline. The elemental and total mercury reach baseline at approximately the same time. This behavior of mercury in the presence of chlorine is not imitated by mercury without chlorine. Step changes in mercury concentration with no presence of chlorine are immediately evident in the outlet concentrations. 


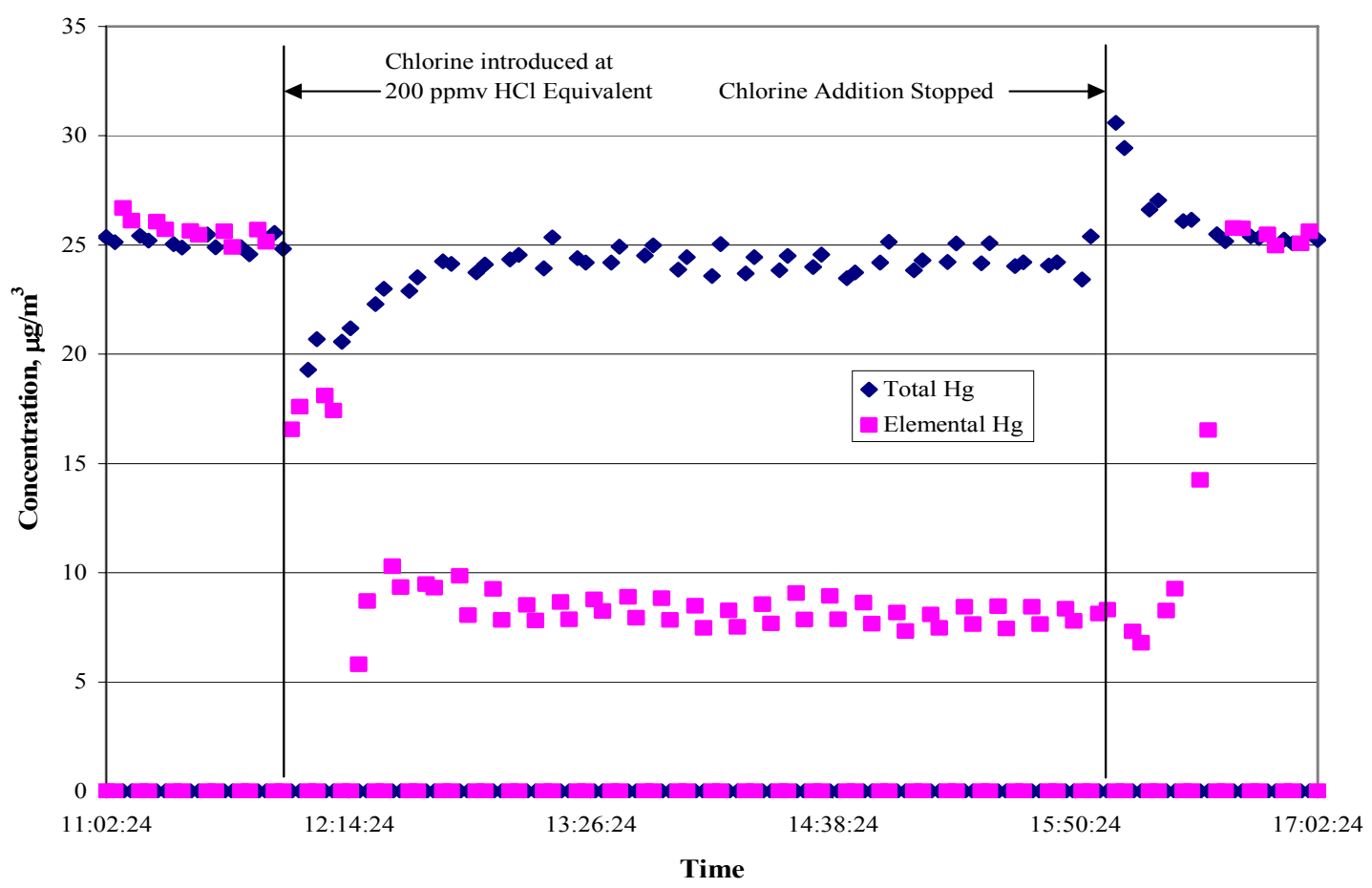

Figure 7

Mercury Speciation Data Showing Adsorption and Desorption of Mercury

It is speculated that the deviation from baseline of the total mercury concentration represents adsorption of mercury on the quartz surfaces just after chlorine addition and desorption of mercury just after chlorine is eliminated. There are many mechanisms that can explain this behavior. The simplest of these would be the adsorption of chlorine species onto the quartz. These adsorbed species could then attract mercury to the surface. The area under the curve (between baseline and total mercury concentration) represents the amount of mercury adsorbed. Experiments were performed to determine the effect of chlorine concentration on the amount of mercury adsorbed. A summary of these data is presented in Figure 8. It is clear that chlorine concentration has a substantial effect on the amount of mercury adsorbed.

To identify the contributions of this heterogeneous phenomenon, more experiments must be performed. It is clear that mercury is adsorbed onto the surface of quartz in the presence of chlorine. It is not clear whether transformations are occurring on the surface and the rate at which these species are desorbed and replaced during the steady state. 


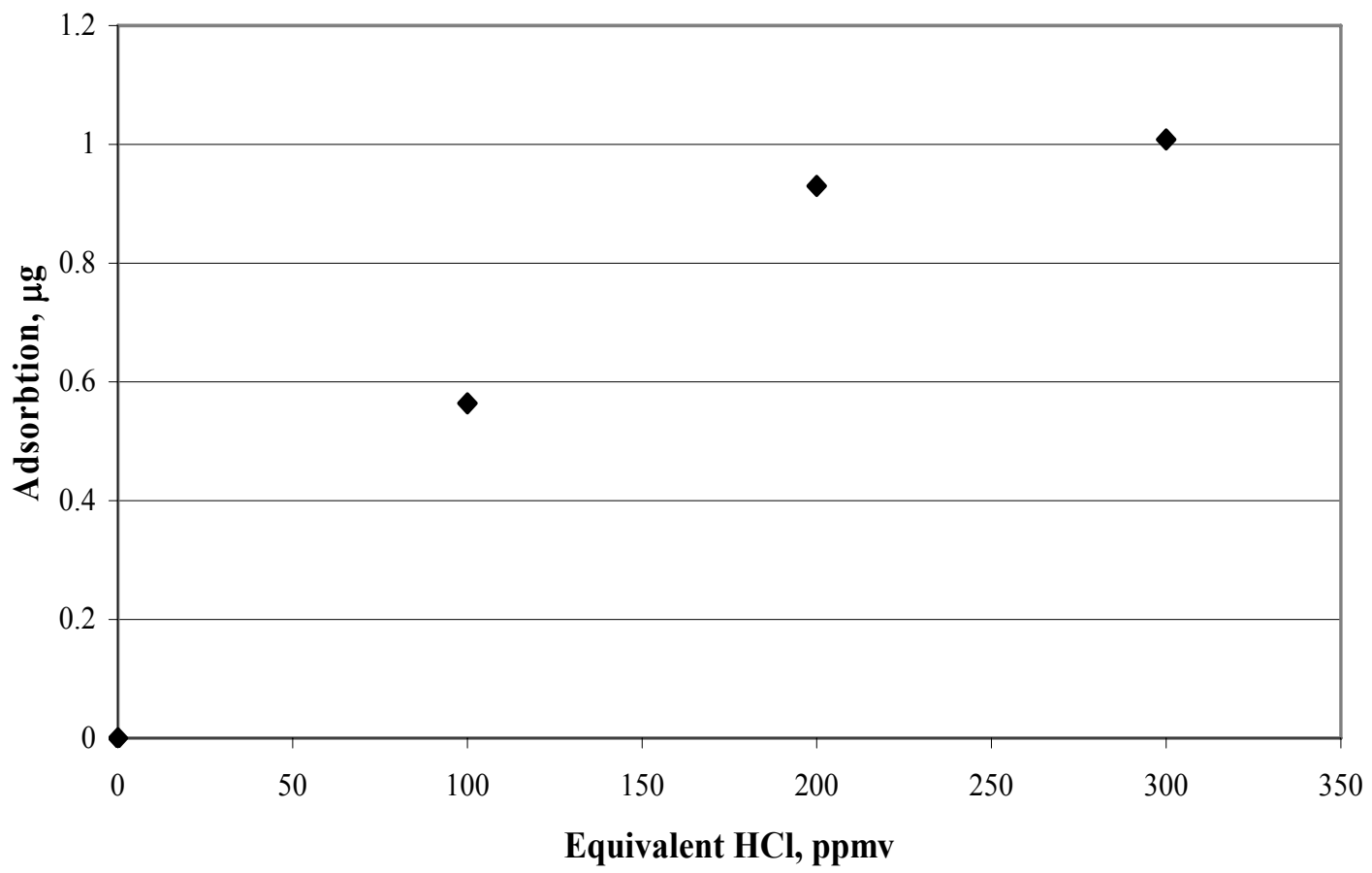

Figure 8

Mercury Adsorption Dependence on Chlorine Concentration

\section{MODELING CHEMISTRY IN MERCURY FLUE GAS}

Helble and co-workers (Qiu, et al. 2003) have studied the post-flame homogeneous reactions of mercury and have developed a detailed chemical kinetic mechanism to describe these reactions (referred to as the UConn mechanism). The mechanism includes sub-models for $\mathrm{Hg}$ chemistry, $\mathrm{Cl}$ chemistry, $\mathrm{NO}_{x}$ chemistry (including $\mathrm{NO}-\mathrm{Cl}$ ) and $\mathrm{SO}_{\mathrm{x}}$ chemistry. Included in the mercury sub-model are the following eight reactions:

$$
\begin{aligned}
& \mathrm{Hg}+\mathrm{Cl}+\mathrm{M}=\mathrm{HgCl}+\mathrm{M} \\
& \mathrm{Hg}+\mathrm{Cl}_{2}=\mathrm{HgCl}+\mathrm{Cl} \\
& \mathrm{Hg}+\mathrm{HCl}=\mathrm{HgCl}+\mathrm{H} \\
& \mathrm{Hg}+\mathrm{HOCl}=\mathrm{HgCl}+\mathrm{OH} \\
& \mathrm{HgCl}+\mathrm{Cl}_{2}=\mathrm{HgCl}_{2}+\mathrm{Cl} \\
& \mathrm{HgCl}+\mathrm{Cl}+\mathrm{M}=\mathrm{HgCl}_{2}+\mathrm{M} \\
& \mathrm{HgCl}+\mathrm{HCl}=\mathrm{HgCl}_{2}+\mathrm{H} \\
& \mathrm{HgCl}+\mathrm{HOCl}=\mathrm{HgCl}_{2}+\mathrm{OH}
\end{aligned}
$$

This reaction mechanism was derived from previous work in the literature. Reaction 1 is thought to be the major kinetic pathway for mercury oxidation. For this reason an accurate chlorine mechanism is a fundamental part of the mercury oxidation model. The chlorine mechanism, including the chlorine recombination reaction, used in this model was developed by Roesler (1994) and consists of 29 reactions. Further, sensitivity analyses on modeling studies in this 
effort and in literature indicate that the chlorine recombination step (Reaction 9) is crucial in determining the $\mathrm{Cl}$-atom concentration in the post-combustion quench stage. Three chlorine recombination reaction rate parameters are available in literature for the reaction:

$$
\mathrm{Cl}+\mathrm{Cl}+\mathrm{M}=\mathrm{Cl}_{2}+\mathrm{M}
$$

Bozzelli and co-workers (Ho et al., 1995), Roesler (1994) and Wilcox (2004) have reported reaction rate parameters for the above reaction that are of the form $\mathrm{k}=\mathrm{A} \mathrm{T}^{\mathrm{n}} \exp (-\mathrm{E} / \mathrm{RT}), \mathrm{cm}-\mathrm{atm}$ $\mathrm{K}$-cal-mole and Table 1 lists these values.

Table 1. Reaction Rate Parameters for Reaction 9.

\begin{tabular}{|c|c|c|c|}
\hline & A & $\mathrm{n}$ & $\mathrm{E}$ \\
\hline Bozzelli & $5.74 \mathrm{E}+14$ & 0 & -1600 \\
\hline Dryer & $4.68 \mathrm{E}+14$ & 0 & -1800 \\
\hline Wilcox* & $1.20 \mathrm{E}+14$ & 0 & 20030 \\
\hline
\end{tabular}

* Note that Wilcox parameters are for the reverse of Reaction 9.

The investigators wanted to determine which reaction set is valid for the conditions studied. These recombination reactions were evaluated independently by coupling with the UConn mercury mechanism (Reactions 1-8) and the Wilcox mechanism. The Wilcox mercury mechanism consists of seven reactions and is slightly different than the UConn scheme. These details are available in Wilcox (2004) and are omitted here.

For the comparisons, previous UConn experiments reported by Sterling et al (2004) at the following conditions where used: equivalence ratio $(\phi)=0.9,50 \mu \mathrm{g} / \mathrm{Nm}^{3} \mathrm{Hg}$ and $150 \mathrm{ppmv} \mathrm{HCl}$. The experimental value of oxidation was $10 \%$. The initial species composition was determined using equilibrium at $1136 \mathrm{~K}$ and remainder of the T-profile was followed (shown in Figure 9).

The chemical kinetic analysis was performed using two mercury mechanisms and three different chlorine recombination rates. The effects of the recombination rate on chlorine speciation are presented in Figure 9 using the UConn mercury mechanism, consisting of eight reactions of mercury, and Figure 10 using the Wilcox mercury mechanism, including seven reactions of mercury. Both were evaluated using the UConn sub-mechanism for flue gas constituents.

Roesler and Bozzelli $\mathrm{Cl}$ recombination reactions produced almost identical chlorine profiles and $\mathrm{Hg}$ oxidation for the corresponding $\mathrm{Hg}$ kinetic schemes, in contrast to Wilcox's reaction where $\mathrm{Cl}$ quenching began at $<0.5 \mathrm{~s}(1050 \mathrm{~K})$ and almost all $\mathrm{Cl}$ was converted to $\mathrm{Cl}_{2}$ by $1 \mathrm{~s}$. In the other two reactions, quenching begins at about $750 \mathrm{~K}$ and peak $\mathrm{Cl}$ levels were at least 3-fold of that predicted by Wilcox. Hence due to low $\mathrm{Cl}$ levels and faster quenching, one obtains near zero oxidation using Wilcox's $\mathrm{Cl}$ recombination reaction. Table 2 lists these results, remembering that the experimental value was $10 \%$ oxidation. 


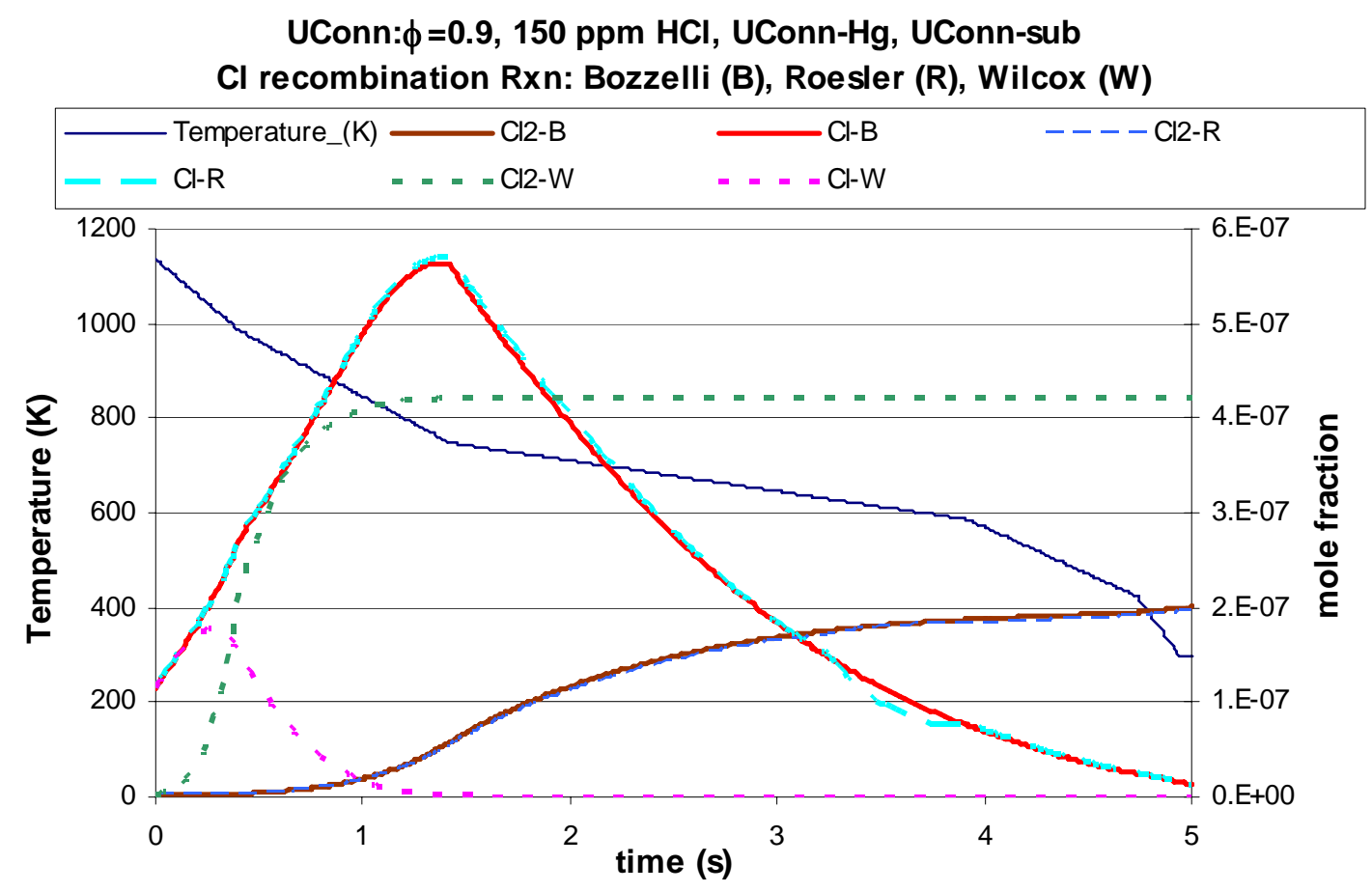

Figure 9. UConn $\mathrm{Hg}$ reactions analyzed using three chlorine recombination reactions

UConn: $\phi=0.9,150$ ppm HCl, Wilcox-Hg, UConn-sub Cl recombination Rxn: Bozzelli (B), Roesler (R), Wilcox (W)

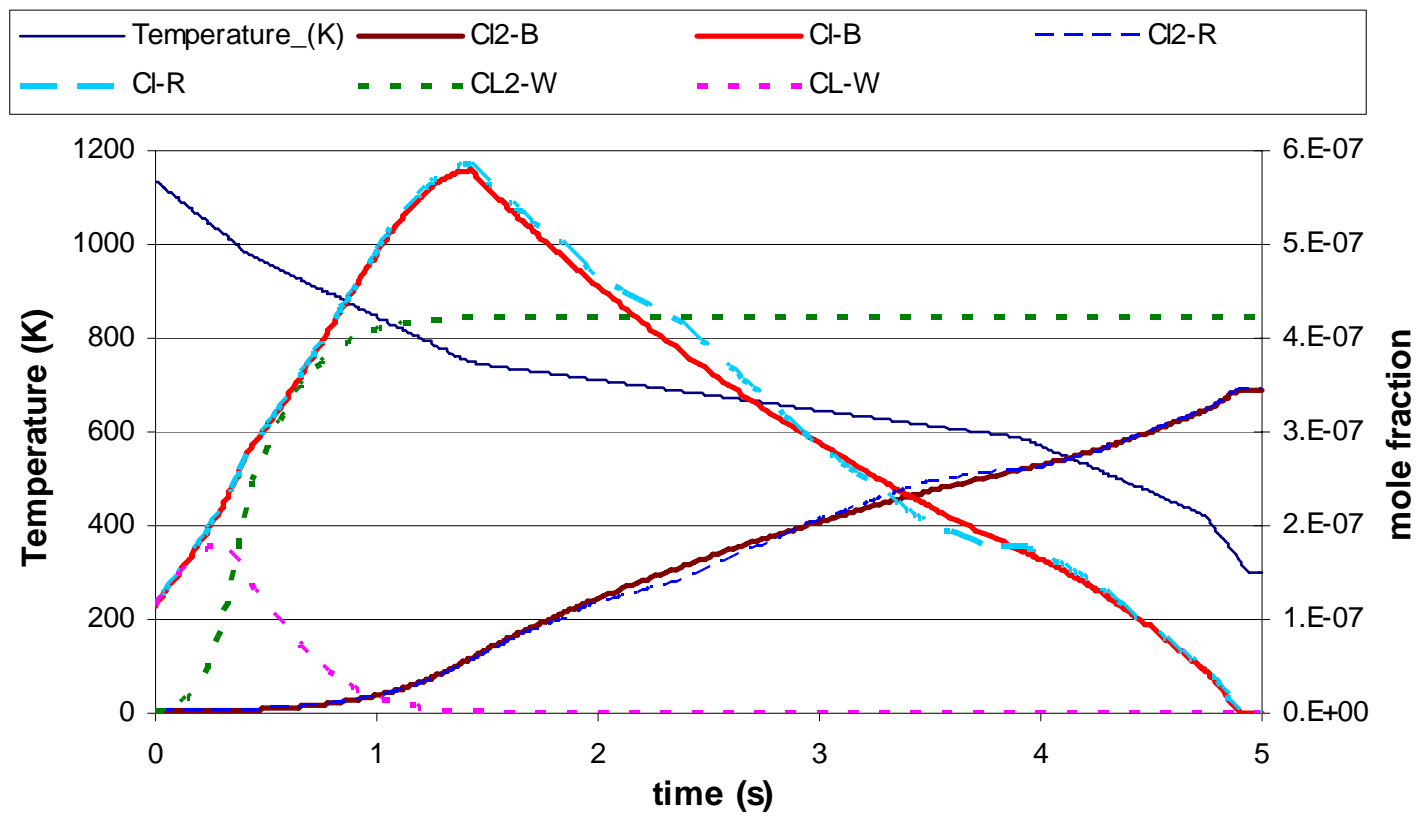

Figure 10: Wilcox $\mathrm{Hg}$ reactions analyzed using three chlorine recombination reactions 
Table 2. Mercury Oxidation under Different Chlorine and Mercury Reaction Mechanisms

\begin{tabular}{|c|c|}
\hline \multicolumn{2}{|c|}{ UConn Hg Mechanism } \\
\hline Chlorine Mechanism & Per Cent Oxidation \\
\hline Bozzelli Chlorine & 18.15 \\
\hline Roesler Chlorine & 18.01 \\
\hline Wilcox Chlorine & 0.08 \\
\hline \multicolumn{2}{|c|}{ Wilcox Hg Mechanism } \\
\hline Chlorine Mechanism & Per Cent Oxidation \\
\hline Bozzelli Chlorine & 64.1 \\
\hline Roesler Chlorine & 65.8 \\
\hline Wilcox Chlorine & 0.01 \\
\hline
\end{tabular}

In addition the Wilcox mercury mechanism gave higher results for mercury oxidation using the Bozzelli, Roesler kinetics for chlorine recombination. Similar behavior was also observed while repeating the analysis for the experimental data presented earlier in this report. We have determined that the chlorine recombination reaction rate appears to be the one that is driving the low mercury oxidation given by recent communications with Wilcox. We have continued to work on this issue.

To compare the experimental data with the modeling, Chemkin 4 was used as the computational platform for this investigation. Two reactors were used. A perfectly stirred reactor (PSR) was used to react natural gas with air to generate a representative initial radical pool and flue gas matrix for the mercury reactions. A plug flow reactor (PFR) was used to model the mercury reactor. The gas composition generated by the PSR was used as an inlet stream to the PFR. Mercury and chlorine were added to this inlet stream. For modeling purposes it was assumed that all of the chlorine entering the PFR was atomic as it passed through the flame. The highand low-quench temperature profiles of the mercury reactor were each used as the temperature profile of the PFR in the model. Volumetric flow was set equal to the flow used in the mercury oxidation experiments and the diameter and length of the PFR were set equal to those of the mercury reactor. The UConn mercury and Roesler/Dryer Chlorine reactions were used.

\section{THEORETICAL STUDY}

In addition to experimental and modeling work, a theoretical study based on quantum chemistry ( $a b$ initio and density functional theory) coupled to transition state theory was initiated to obtain refined rate constants for reactions in the mercury mechanism as well as in the supporting submechanism. Gaussian03W was used as the computational software for these calculations.

Preliminary work concluded thus far involves the study of Reaction 1 using several quantum methods and basis sets. These methods/basis sets are required to determine the structure and properties of the transition state, which in turn shall be used to estimate rate constants.

As transition structures and their associated properties are not observable, the choice of method/basis set must be based on validations of observable properties of reactants and products. Table 3 presents the comparisons between experimental measurements and theoretical calculations for enthalpy, equilibrium geometry and vibrational frequency using different 
combinations of method/basis sets. Five basis sets and several methods were studied and the results for selected ones based on agreement with experimental values are tabulated below. The LanL2MB basis set produced the maximum absolute error in $\mathrm{HgCl}$ bond length ranging from 0.2 to $0.34 \AA$ for all methods. The enthalpy of reaction for $\mathrm{HgCl}=\mathrm{Hg}+\mathrm{Cl}$ also showed the highest deviation from the measured value for this basis set and therefore, it would not be considered for further calculations involving $\mathrm{HgCl}$.

Table 3. Comparison of Experimental and Calculated Parameters for $\mathrm{HgCl}$

\begin{tabular}{|c|c|c|c|}
\hline Method/Basis Set $^{\mathrm{a}}$ & $\begin{array}{c}\text { Equilibrium } \\
\text { Bondlength } \\
\text { (R), } \AA\end{array}$ & $\begin{array}{c}\Delta \mathrm{H}_{\mathrm{Rxn}}(\mathrm{kJ} / \mathrm{mol}) \\
\operatorname{Rxn}: \mathrm{HgCl}=\mathrm{Hg}+\mathrm{Cl}\end{array}$ & $\begin{array}{c}\text { Harmonic } \\
\text { Frequency } \\
(\mathrm{v}), \mathrm{cm}^{-1}\end{array}$ \\
\hline \multicolumn{4}{|l|}{ ab initio: } \\
\hline HF/CEP-121G & 2.485 & 54.67 & 281.52 \\
\hline HF/LanL2DZ & 2.622 & 63.05 & 287.26 \\
\hline HF/SDDAll & 2.484 & 50.65 & 281.60 \\
\hline QCISD/CEP-121G & 2.494 & 60.84 & 264.99 \\
\hline QCISD/SDD & 2.497 & 52.98 & 263.05 \\
\hline QCISD(T)/CEP-121G & 2.495 & 60.84 & 264.03 \\
\hline QCISD(T)/LanL2DZ & 2.519 & 51.53 & 264.31 \\
\hline QCISD(T)/SDD & 2.499 & 54.09 & 261.48 \\
\hline QCISD(T)/SDDAll & 2.500 & 58.82 & 260.43 \\
\hline MP2/CEP-121G & 2.469 & 62.79 & 282.12 \\
\hline MP2/SDDAll & 2.470 & 54.65 & 280.49 \\
\hline MP4(SDTQ)/CEP-121G & 2.479 & 56.32 & 274.52 \\
\hline MP4(SDTQ)/SDD & 2.483 & 48.24 & 271.06 \\
\hline \multicolumn{4}{|l|}{ Density functional: } \\
\hline B3LYP/LanL2DZ & 2.612 & 102.85 & 227.71 \\
\hline BLYP/LanL2DZ & 2.664 & 107.44 & 210.88 \\
\hline Experimental & $2.42^{b}$ & $104.25^{c}$ & $292.61^{c}$ \\
\hline
\end{tabular}

Based on the above-mentioned calculations, the MP2 and QCISD methods seem appropriate for the determination of structure and energies of the activated complex. Although the HF method predicts relatively accurate geometry and frequency, it is generally used only as a primer for calculations as it does not incorporate any electron correlation effects. The density functional methods predict enthalpy accurately but significantly deviate from the other parameters, which might result in inaccurate properties of the transition structure, nevertheless, these shall be considered further in this work. Additionally, many correction terms such as scaling factors can 
be employed for the above calculations that might result in marginal to significant deviation in the calculated parameters. As these are empirical values, however, discretion is required in their selection. Overall, as it is difficult to identify uniquely a method/basis set combination, our future work will consider $\mathrm{Hg}$ oxidation modeling using quantum chemistry derived rate constants as an indication of accuracy. Work is progressing in that direction.

\section{RESULTS AND DISCUSSION}

In this section, the results of the modeling, compared with the experiments are presented. The input chlorine concentration to the model was varied from 0 to 600 ppmv using each of the mercury reactor temperature profiles. Curves for percent oxidation vs. equivalent $\mathrm{HCl}$ concentration were generated. Figure 11 details model predictions for oxidation using the high quench temperature profile against experimental data.

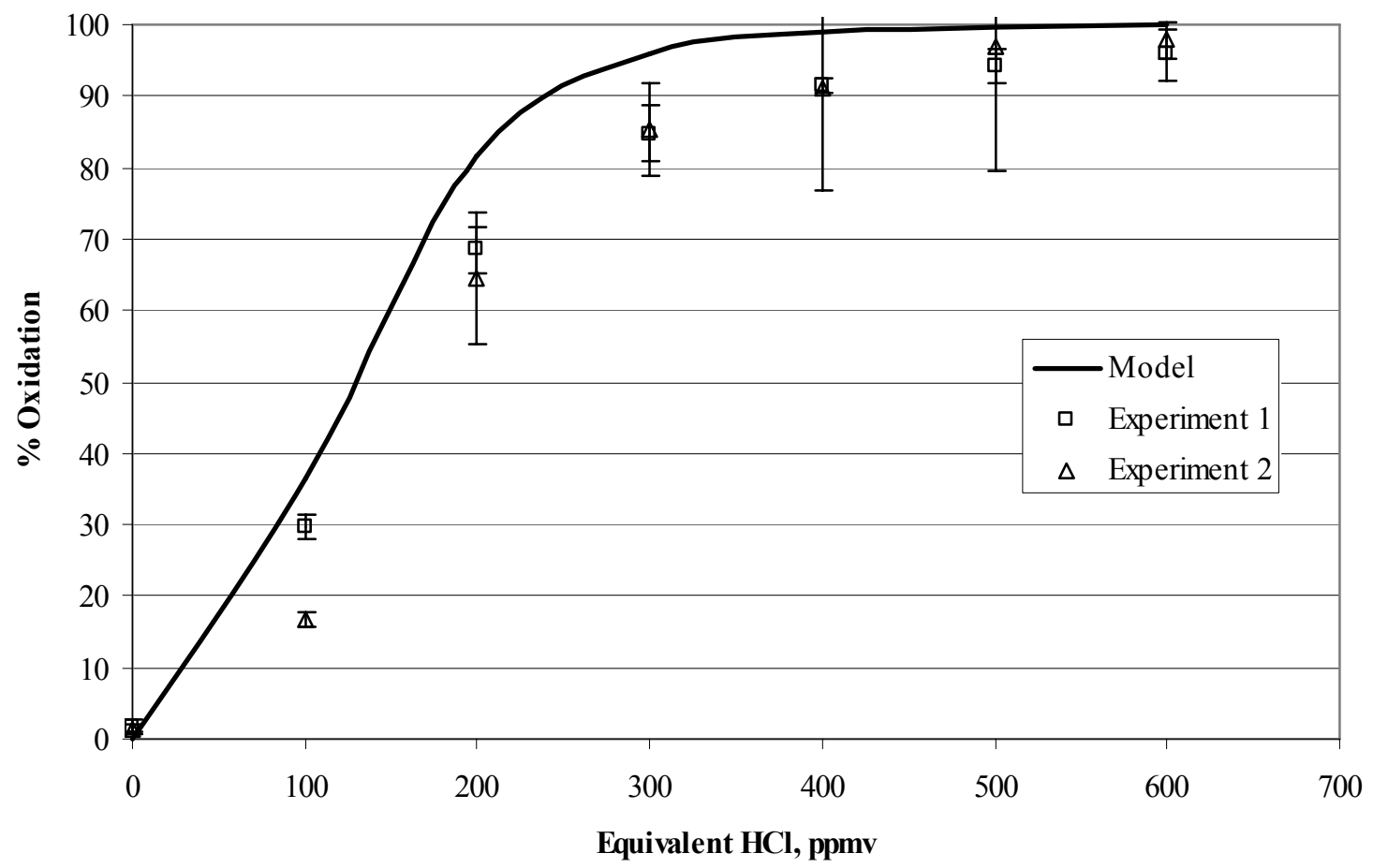

Figure 11. Comparison of Model Prediction and Experiment, High Quench Temperature Profile

Figure 12 details model predictions for oxidation using the low quench temperature profile against experimental data. 


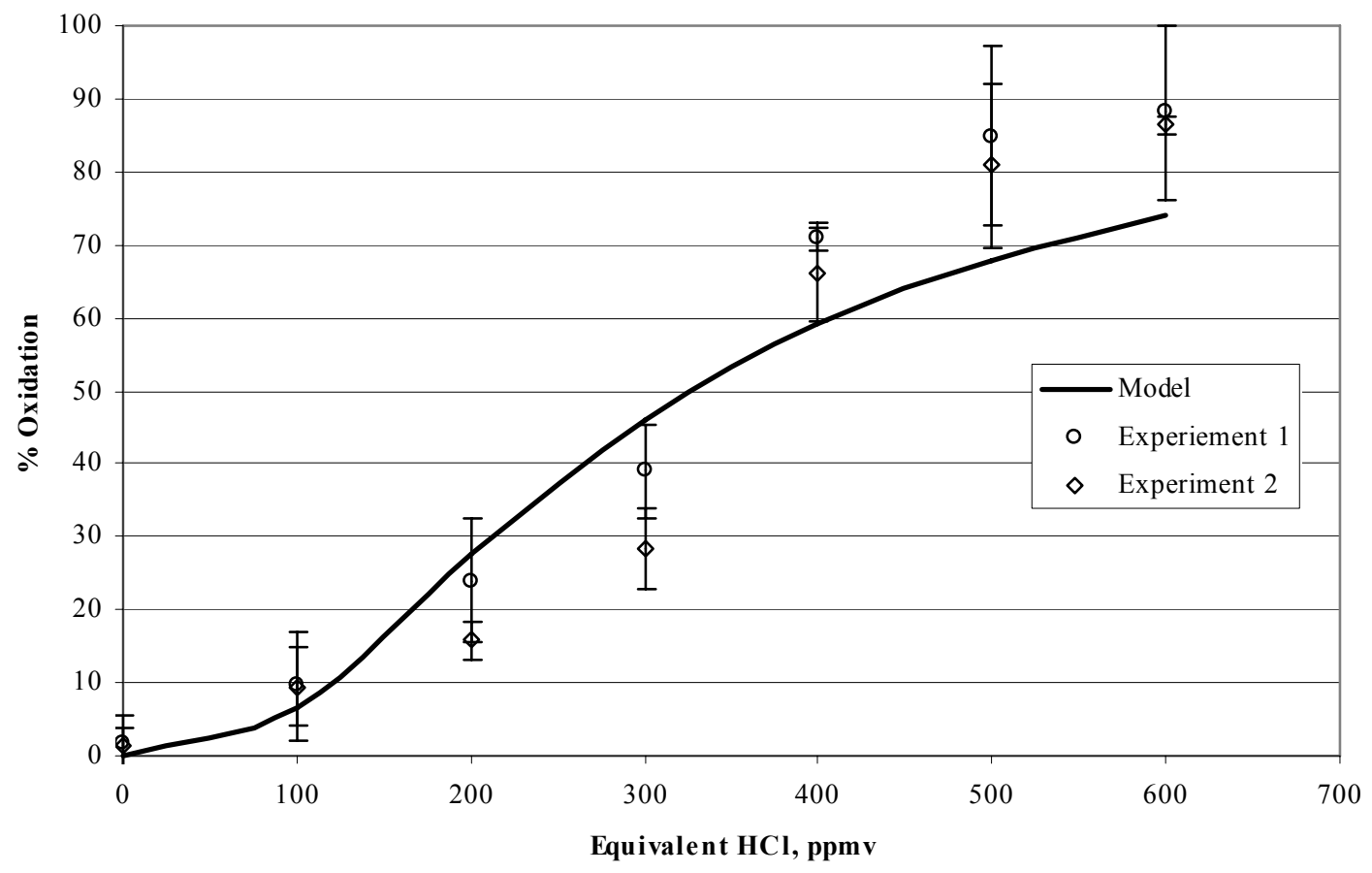

Figure 12

Comparison of Model Prediction and Experiment

Low Quench Temperature Profile

The model has also been shown to predict the experimental results published by Sliger et al. (2000) and by Mamani-Paco et al. (2000). These experiments were significantly different from the experimental conditions in the present study (as detailed in Figure 5). Sliger et al. used a larger, refractory-lined furnace and a very high quench rate in the sampling system (and thus a short residence time); mercury was injected through the burner, but $\mathrm{HCl}$ was injected downstream of the flame. Mamani-Paco et al. used a quartz reactor and injected mercury and chlorine species into a mixing chamber downstream of the flame. In spite of the differences among the experimental set-ups, the homogeneous model was robust enough to predict the mercury oxidation results in all three experiments, over a range of chlorine concentrations and quench rates.

\section{CONCLUSIONS}

The accomplishments during the second year have included:

- Experimental runs varying the quench rate, chlorine concentration, and sulfur dioxide concentration.

- Experimental runs investigating surface area effects.

- Verification of submodels for mercury and chlorine.

- Comparison of modeling with data. 
During this next year, we will continue to investigate the effects of surface area on homogeneous oxidation. In addition we will begin packed bed and disperse phase experiments on coal constituents, namely iron and calcium. The initial theoretical calculations using quantum chemistry and transition state theory will be completed to improve the existing model and to determine additional reaction rate parameters. We are also working with Professor Jennifer Wilcox and coordinating some efforts with her transition state theory modeling results. Effort in this direction has already been initiated and some preliminary results are available.

\section{PRESENTATIONS and PUBLICATIONS}

A. R. Fry, J. S. Lighty, and G. D. Silcox, "Fundamental Homogeneous Reactions of Mercury in Coal Fired Utility Boilers," presented at the $9^{\text {th }}$ International Congress on Toxic Combustion By-Products: Origin, Fate and Health Impacts, Tucson, AZ, June 2005.

A. Fry, J. S. Lighty, G. D. Silcox, B. Cauch, "Fundamental Homogeneous Reactions of Mercury in Coal Fired Utility Boilers," presented at the "30th International Technical Conference on Coal Utilization \& Fuel Systems," Clearwater, FL, April 17-21, 2005.

Senior, C., Sadler, B., Sarofim, A. "Modeling Mercury Behavior in Practical Combustion Systems" presented at the American Chemical Society National Meeting, San Diego, CA, March 13-17, 2005.

\section{ACKNOWLEDGEMENTS}

This annual report was prepared with the support of the U.S. Department of Energy, under Award No. DE-FG26-03NT41797. However, any opinions, findings, conclusions, or recommendations expressed herein are those of the authors and do not necessarily reflect the views of the DOE.

\section{REFERENCES}

Bhartiya, J.B., Behere, S.H., Rao, M.L.P., "Dissociation Energies of $\mathrm{HgCl}, \mathrm{HgBr}$ and $\mathrm{HgI}$ from Potential Energy Curves", Journal of Quantitative Spectroscopy and Radiative Transfer, 43, 9598, 1990.

Gaussian03W: M. J. Frisch, G. W. Trucks, H. B. Schlegel, G. E. Scuseria, M. A. Robb, J. R. Cheeseman, J. A. Montgomery, Jr., T. Vreven, K. N. Kudin, J. C. Burant, J. M. Millam, S. S. Iyengar, J. Tomasi, V. Barone, B. Mennucci, M. Cossi, G. Scalmani, N. Rega, G. A. Petersson, H. Nakatsuji, M. Hada, M. Ehara, K. Toyota, R. Fukuda, J. Hasegawa, M. Ishida, T. Nakajima, Y. Honda, O. Kitao, H. Nakai, M. Klene, X. Li, J. E. Knox, H. P. Hratchian, J. B. Cross, C. Adamo, J. Jaramillo, R. Gomperts, R. E. Stratmann, O. Yazyev, A. J. Austin, R. Cammi, C. Pomelli, J. W. Ochterski, P. Y. Ayala, K. Morokuma, G. A. Voth, P. Salvador, J. J. Dannenberg, V. G. Zakrzewski, S. Dapprich, A. D. Daniels, M. C. Strain, O. Farkas, D. K. Malick, A. D. Rabuck, K. Raghavachari, J. B. Foresman, J. V. Ortiz, Q. Cui, A. G. Baboul, S. Clifford, J. 
Cioslowski, B. B. Stefanov, G. Liu, A. Liashenko, P. Piskorz, I. Komaromi, R. L. Martin, D. J. Fox, T. Keith, M. A. Al-Laham, C. Y. Peng, A. Nanayakkara, M. Challacombe, P. M. W. Gill, B. Johnson, W. Chen, M. W. Wong, C. Gonzalez, and J. A. Pople, Gaussian, Inc., Pittsburgh PA, 2003.

Ghorishi, S.B., Fundamentals of Mercury Speciation and Control in Coal-Fired Boilers, EPA600/R-98-014, February 1998.

Ho, W., Booty, M.R., Magee, R.S., Bozzelli, J.W., “Analysis and Optimization of Chlorocarbon Incineration through the Use of a Detailed Reaction Mechanism", Industrial \& Engineering Chemistry Research, 34, 4185-4192, 1995.

Mamani-Paco, R.M., Helble, J.J., "Bench-Scale examination of Mercury Oxidation under NonIsothermal Conditions," Proceedings of Air \& Waste Management Association $93^{\text {rd }}$ Annual Conference and Exhibition, Salt Lake City, UT, June 19-22, 2000.

Procaccini, C., et al. "Presence of Chlorine Radicals and Formation of Molecular Chlorine in the Post-Flame Region of Chlorocarbon Combustion," Environmental Science and Technology, 34, 4565-4570, 2000.

Qiu, J., Sterling, R.O., Helble, J.J. "Development of an Improved Model for Determining the Effects of $\mathrm{SO}_{2}$ on Homogeneous Mercury Oxidation." Presented at the 28th International Technical Conference on Coal Utilization \& Fuel Systems, Clearwater, FL, March 10-13, 2003.

Roesler, J.,"The Effects of Chlorine on the Oxidation Kinetics of Hydrocarbons and Carbon Monoxide", Ph.D. Thesis, Department of Mechanical and Aerospace Engineering, Princeton University, Princeton, NJ, Jan. 1994.

Sliger, R.N.; J.C. Kramlich; N.M. Marinov. "Towards the development of a chemical kinetic model for the homogeneous oxidation of mercury by chlorine species," Fuel Process. Technol. 65-66: 423-438 (2000).

Sterling, R.O., Qiu, J.R., Helble, J.J., "Experimental Study of Mercury Homogeneous Reaction Chemistry Under Post-Flame Conditions", Presented at the $227^{\text {th }}$ Spring ACS National Meeting, Anaheim, CA (2004).

Wilcox, J., "On the Path to Elucidating the Speciation of Mercury in the Flue Gases of Coal Combustion", Ph.D. Thesis, Department of Chemical and Environmental Engineering, University of Arizona (2004).

World Wide Web: http://webbook.nist.gov/chemistry/ (date accessed: July 2005) 